\title{
Exploration on Teaching Model of the "Internet Plus CNC Technology" in University Courses
}

\author{
Dongfang $\mathrm{HU}^{1, a}$, Yafei ZHENG ${ }^{1, b}$ \\ ${ }^{1}$ School of Mechatronics Engineering, Henan University of Science and Technology, Luoyang, \\ 471003, China \\ aemail: hdf@haust.edu.cn, bemail: ilovfe@163.com
}

\begin{abstract}
Keywords: Internet Plus CNC Technology; Teaching Model; Network Technology; Bilingual Interactive Teaching
\end{abstract}

\begin{abstract}
The combination of the Internet and the traditional classroom has redefined the way of gaining knowledge. The limitations of traditional classroom teaching have been broken by Internet. Internet re-integrates high-quality educational resources, which stimulate students to learn actively and independently. "Internet plus CNC technology" teaching model has been proposed in the process of education and teaching of undergraduate courses. The advanced network technology, teaching facilities, research progress of CNC technology at home and abroad has been used in this model, which can effectively cultivate and inspire students' autonomous learning and self-improvement. At the same time, to carry out bilingual interactive teaching, introducing advanced international education concepts and methods to break through the university students' ways of inherent thinking. It has demonstrated that "Internet plus CNC technology" teaching model can enhance the research ability and innovation ability of the students. The model can improve their professional quality and comprehensive ability, and broaden the horizons of students. And ultimately the awareness of the international competition of contemporary students is greatly increased.
\end{abstract}

\section{Introduction}

Along with the rapid development of the Internet, the form of information dissemination has been developed from the most ancient oral communication, text communication, printing to today's electronic communication [1]. As the way of information dissemination changes, especially when the change of knowledge dissemination is a challenge to the traditional education in classroom teaching, students are no longer limited to fixed classroom to gain knowledge; they can through a variety of channels, such as the "public class", "Excellent Courses" and "micro classroom", to acquire knowledge. In these channels the majority of domestic and foreign teachers who can explain profound theories in simple language are famous for their good teaching. This subversion of the traditional learning experience in a large extent may stimulate the students' learning enthusiasm and initiative

Numerical control technology is the technology that uses digital quantity and character to issue commands and realize automatic control [2]. It is the basic technology of manufacturing industry to realize automation, flexible and integrated production. Numerical control technology and equipment leads the traditional manufacturing industry which has undergone major changes. It is the most basic equipment of developing new high-tech industry and enabling technology; and it is an important indicator to measure a country industrial productivity. With the transformation and upgrading of China's manufacturing industry, students who are qualified the knowledge and skills of CNC technology and equipment have become more and more popular in modern enterprises. Numerical control technology and equipment, as an undergraduate course, should be in order to cultivate the talents for modern enterprises. It is necessary for college students to build a solid foundation on theoretical knowledge, but also to make them possess the ability to practice what they learn. Modern enterprises claim that CNC talents must be qualified with professional quality: to operate CNC machine tools, to understand and to optimize CNC technology, master NC 
programming of CNC lathe, CNC milling machine and machining center, and skills to develop a variety of CNC equipment.

In order to achieve this goal, we explore "Internet plus CNC technology" teaching mode -- the combination of Internet resources and traditional classroom teaching and the method of using multimedia organization nonlinear network structure information -- to help students build knowledge structure system. Bilingual teaching, through the interaction of the English classroom to stimulate students' interest in learning the course, is used to cultivate students' ability of self-thinking, self-understanding, self-practice and self-innovation [3].

\section{Framework for the Knowledge Structure of the System Based on the Internet}

With the popularity of the Internet, especially the rapid development of mobile Internet, learning at any time and at any time has come true. Intelligent terminal of mobile devices (smart phones, tablet PCs, etc.) will gradually become the manpower necessary basic tools. The authority of educational resources is integrated together by "open class", "micro class" app. To absorb knowledge on mobile devices has been became a trend. On the Internet a high quality and rich educational resources are conveniently reached. These developing resources will gradually be formed a complete system of knowledge structure in the Internet. More and more intelligent terminals have been accessed to the internet, so the teachers' role should be properly switched from traditional teaching mode to the tutors. Students can study at home and abroad to gain high-quality courses on the Internet where they may be difficult to read in the process of learning and encounter problems which they cannot understand. And then through traditional classroom answering questions for students the tutors can cultivate students' ability to solve the problem. The teaching model of "Internet+" sees Fig. 1.

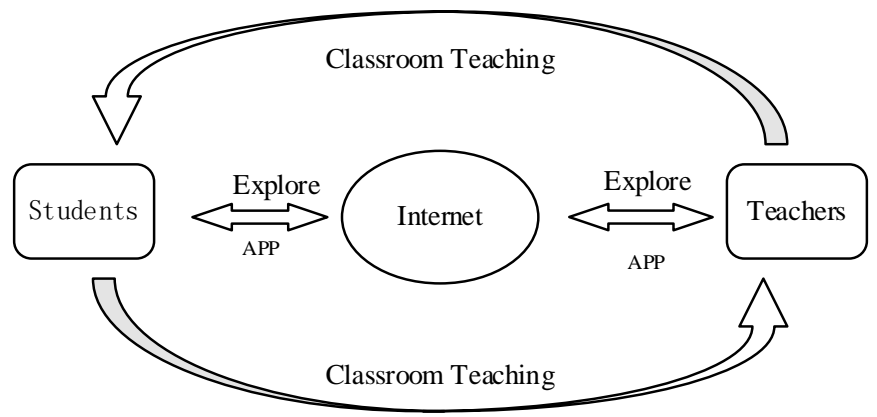

Fig.1. The teaching model of "Internet+"

Through multimedia technology the abstract and obscure theory may be transformed into a simple and clear image and animation which helps students to understand and digest the difficulties in the teaching process. Multimedia technology has characteristics of the flexibility, real-time, and advancing with the times. As current cutting-edge products and technologies is introduced on the traditional textbooks, multimedia technology is used to broaden students' horizons, stimulated their interest of NC technology, and trained their creative thinking. Multimedia technology is very suitable for interdisciplinary course teaching, especially in the NC technology which is constituted by microelectronics, computer and modern control science. It which enriches the resources helps students to construct a systematic and complete knowledge structure and enhance their understanding of knowledge. The advanced numerical control technology research achievements, which provide a good material foundation for the students' independent study both at home and abroad, are shared by “Open class”, "excellent course” and so on.

Nowadays professional curriculum textbooks in most of the universities is edited by a few years ago. Although the basic principle of textbooks will not be changed over time, but new products, new technology update faster. Traditional textbooks already cannot be satisfied with the needs of modern classroom, and must be added the advanced teaching means and methods, such as multimedia and network technology. In order to inspire students to think independently the development direction of numerical control technology and equipment, the domestic and foreign 
advanced numerical control technology research should be introduced into the classroom [4]. So teachers can guide students to find the reasons for the gap of the domestic and abroad CNC technology.

The west of Henan Province Network Center, which is with high-speed campus network, is in our school. Campus network is connected to the China Education and research network, on which students can study at provincial and national level quality course. The latest achievements of domestic and foreign numerical control technology teaching resources and technology are shared on these websites, which greatly enrich ways for students to obtain information. Under the guidance of teacher, these high quality CNC technology resources at home and abroad may be used to trained students' interests, which can lead them to find problems and research directions and complement teachers' teaching content. This teaching model can effectively enhance students' understanding of NC technology, and inspire their innovative consciousness and thinking. More important, the model can actively improve students' ability of innovation. In addition, to develop network teaching, numerical control technology curriculum website has been established in our school. Online Q\&A, online homework, online exercises and online simulation experiment are applied to help students to do training and self-test. Course website is not only convenient for students to review the knowledge and the online self-test, but also can quickly give students feedback online results. It provides a valid solution for students to review timely and consolidate knowledge in the learning process. Through online Q\&A platform, students can to ask questions to the teacher at any time; on the other hand, the teacher will give students a reply in the fastest time based on this platform. Students do not need to accumulate questions and wait teachers to answer, which in a large extent improves the student learning quality and efficiency and the teaching quality of teachers. This teaching model also effectively inspires students' enthusiasm of learning and sets up the learning atmosphere of questioning.

The multimedia equipment in schools should be maintained and even replaced on time, so as to avoid the influence of the quality which is caused by the multimedia equipment failures. PPT, that teachers prepared, should not be transcribed in the textbook. It must do focus and clarity for students to learn. In addition, as far as possible using the heuristic teaching method, the teacher in the multimedia teaching, firstly put forward the problem, secondly guide students to think actively, and lastly make the students more efficient absorption and master knowledge.

\section{Use of Bilingual Interactive Teaching Model, to Train Innovative Talents, to Train the Overall Quality of Students}

Under the background of economic globalization, Bilingual teaching is an effective way to cultivate innovative and inter-disciplinary talents. Through the introduction of advanced foreign teaching ideas and methods, the student's inherent mode of thinking should be broken through. Students should also be enabled with an international perspective and sense of creativity. Through this teaching model, students' comprehensive quality and ability can be effectively enhanced. Bilingual teaching, not only can improve the level of professional English of students, but also is the requirements of modern enterprise and society. The limitations of traditional classroom must be broken through the bilingual teaching. To make full use of the Internet's characteristics of open and real-time, such as QQ, WeChat, microblog software and so on, it must be better for students to learn and communicate on the Internet by the guide of teachers. At the same time, their feedback of learning can be given back to teachers as fast as possible through the software. So that students can better grasp the knowledge of CNC bilingual courses and improve their ability to learn CNC professional English.

In 2001, according to the actual situation of the undergraduate teaching and the requirement of the social development in our country, the Ministry of education has made a file: 《Some opinions on strengthening undergraduate teaching work and improving teaching quality $》$, the document pointed out that "education is oriented to the modernization, the world and the future". In order to meet the challenges of economic globalization and technological revolution, the undergraduate education 
should be created conditions to use English or other foreign language to conduct public and specialized course. According to request of the document, colleges and universities should actively respond to the call of the Ministry of education, and strive to promote the use of bilingual teaching. Our school has begun to actively carry out the bilingual teaching of numerical control technology aiming at cultivating the compound and innovative talents in the background of economic globalization [5]. As we all know, our country in the numerical control technology and equipment has made great progress, but compared with foreign countries, especially in high speed and high precision processing technology and equipment field, five axis linkage processing and compound processing machine tool field, and the NC system oriented intelligent, open, network development field, China still has a big gap. Therefore, it is necessary to cultivate students to read foreign journals and scientific research, to develop the international horizon of students, to stimulate students' interest in thoroughly studying the numerical control technology, to improve the ability of innovation, to promote the progress and development of the technology of numerical control of our country. Under the background of global economic integration, modern enterprises ask that contemporary college students should be qualified with a foreign language such as English. Through the bilingual teaching, especially in the process of communication, professional English vocabulary of students will be a subtle increased, professional English ability and professional quality will be promoted. So as to meet the needs of modern enterprises and society.

Bilingual teaching is not equal to the traditional mode of "translation" class. Teachers will not translate foreign language into Chinese with standing on the podium. Old mode cannot reach the goal of training talents. It also may cause students' boredom to learning. The roles of both the students and the teachers have changed on bilingual teaching. Students have become the main character in the classroom. The teacher's role is more like a guide to encourage, guide and correct the mutual discussion and debate among the students [6]. Students choose their own interest about NC technology to communicate with teachers in English which is a common method of classroom teaching in our university. This method is not limited in the classroom. Students also can discuss homework problems with teacher in English. This method can help teacher to guide students to learn according with their different aptitude. It proved that this model greatly stimulates students' autonomous learning ability and improves the students' use of English language and expression ability. In addition, teachers can provide some numerical control technology questions for students to complete in the way of groups, and present them in class. This model requires students to query a large number of documents before class, thus the students' ability of reading foreign literature and professional quality will be improved.

It is necessary for teachers to know the level of the ability of students to master knowledge through some periodic investigation. According that students can understand and master the degree of the basic theoretical knowledge, the proportion of English teaching can be expanded appropriately. So that the students' comprehensive ability and professional quality can be improved. In addition, in the selection of teaching materials, the original and the latest version of the English textbook is the best choice.

\section{Conclusion}

In the process of numerical control technology teaching, our school teachers always adhering to the "heuristic", "guide" teaching methods, in order to train students to find problems, solve problems and improve the ability of themselves. Teaching model of Internet plus CNC technology has been realized in the class so that students effectively understand and grasp the knowledge points. This model also positively stimulates the students' enthusiasm and interest. Through the conversion of the role of teachers and students, model of bilingual teaching can improve students' learning initiative. So as to improve the students' comprehensive quality and ability. The development of mobile Internet and smart phones has impelled the growth of NC Bilingual Teaching. With using instant messaging app, teachers and students can be very relaxing for online tutoring and Q\&A, which effectively improves the learning initiative and enthusiasm. Although our school in the teaching process of NC technique has made certain progress, we should do better. We will make 
every effort to cultivate innovative talents that the motherland needs

\section{Acknowledgement}

The authors gratefully acknowledge the Project for Education and Teaching Reform of Henan University of Science and Technology (No. 2012N-007) and the National Superior Course and Bilingual Teaching Demonstration Course for financial support of this research work.

\section{References}

[1] ZHANG Huabing. Comparative study of Internet content regulation [D]. Beijing: Graduate School of Chinese Academy of Social Sciences, 2011: 1-32.

[2] HAN Jianhai, HU Dongfang. Numerical control technology and equipment [M]. The Second Edition. Wuhan: Huazhong University of Science \& Technology Press, 2007: 1-25.

[3] MIAO Miao, DU Lanfeng. The positive role of bilingual teaching in classroom teaching [J]. Charming China, 2013 (20): 177.

[4] HAN Zhenyu, FU Hongyun, FU Yunzhong, et al. Discussion and Practice on the teaching reform of the course of "numerical control technology" [J]. China University Teaching, 2012 (7): 41-42.

[5] TANG Wei, The trend of the development of numerical control technology and the countermeasures [J]. Scientific Consult. 2013 (1): 158-159.

[6] ZHANG Yi, LI Zhengyuan, DENG Liu. Some reflections and experiences on Bilingual Teaching of Chemistry Majors [J]. Chinese Journal of Chemical Education, 2013, 34 (7): 48-51. 